\title{
Produtos naturais de Momordica charantia L. como moduladores da resistência de Escherichia coli a fármacos antimicrobianos
}

\author{
Samuel de Barros Silva ${ }^{1 *}$, Huga Géssica Bento de Oliveira ${ }^{1}$, Gil Sander Prospero Gama ${ }^{1}$, Raizza Eveline \\ Escórcio Pinheiro ${ }^{1}$, João Sammy Nery de Souza ${ }^{1}$, Thiago Pereira Chaves ${ }^{1}$
}

\begin{abstract}
RESUMO: Objetivou-se avaliar o potencial de produtos naturais da Momordica charantia L. como agente antibacteriano e modulador da resistência de cepas de Escherichia coli a diferentes antibióticos. O extrato etanólico foi obtido a partir da maceração das folhas secas. As cepas multirresistentes utilizadas foram a E. coli 35 e E. coli 208 . A concentração inibitória mínima (CIM) foi determinada pelo método de microdiluição em placas de 96 cavidades. Percebeu-se que, o extrato vegetal não apresentou efeito inibitório frente as cepas testadas (CIM $\left.>1000 \mu \mathrm{g} \mathrm{mL}{ }^{-1}\right)$. Nos ensaios de modulação frente a $E$. coli 35 observou-se redução significativa da CIM da Amoxicilina $(99,2$ para 50,0 $\mu \mathrm{g}$ $\mathrm{mL}^{-1}$ ). Nos ensaios com E. coli 208 a associação do extrato com os diferentes antimicrobianos, verificou-se que houve redução da CIM da Amoxicilina (396,8 para 250,0 $\mu \mathrm{g} \mathrm{mL}^{-1}$ ) e Gentamicina (62,5 para 39,3 $\mu \mathrm{g} \mathrm{mL}^{-1}$ ), enquanto a associação com a Vancomicina não apresentou diferença significativa. Futuros estudos são necessários para identificar quais componentes do extrato foi responsável por tal ação, assim como os mecanismos envolvidos.
\end{abstract}

Palavras-chave: Resistência bacteriana, Antibióticos $\beta$-lactâmicos, Melão-de-São-Caetano.

\section{Natural products of Momordica charantia L. as modulators of Escherichia coli resistance to antimicrobial drugs}

ABSTRACT: The objective was to evaluate the potential of natural products of Momordica charantia $\mathrm{L}$. as antibacterial agent and modulator of the resistance of strains of Escherichia coli to different antibiotics. The ethanolic extract was obtained from the maceration of dry leaves. In the microbiological tests the multi-resistant strains E. coli 35 and $E$. coli 208 were used. The minimum inhibitory concentration (MIC) was determined by the 96-well plate microdilution method. It was observed that the plant extract had no inhibitory effect against the strains tested (MIC $\left.>1000 \mu \mathrm{g} \mathrm{mL}{ }^{-1}\right)$. In the modulating assays against E. coli 35 a significant MIC reduction of Amoxicillin was observed $(99.2$ for $50.0 \mu \mathrm{g}$ $\mathrm{mL}^{-1}$ ). In the assays with $E$. coli 208 the association of the extract with the different antimicrobials, it was verified that there was reduction of Amoxicillin (396.8 to $250.0 \mu \mathrm{g} \mathrm{mL} L^{-1}$ ) and Gentamicin MIC (62.5 to $39.3 \mu \mathrm{g} \mathrm{mL}{ }^{-1}$ ), while the association with Vancomycin did not present a significant difference. Future studies are needed to identify which components of the extract were responsible for such action, as well as the mechanisms involved.

Key words: Bacterial resistance, $\beta$-lactam antibiotics, Melão-de-São-Caetano.

\section{INTRODUÇÃO}

A resistência bacteriana aos antibióticos é apontada como um grande problema de saúde pública que preocupa a sociedade atual e se agrava em virtude do uso inadequado e/ou indiscriminado destes agentes (TENOVER, 2006).

Considerando que o desenvolvimento de novas drogas antimicrobianas não acompanha a evolução da resistência, as cepas bacterianas resistentes a múltiplas classes de antimicrobianos, ocasionam uma limitação das opções de tratamento, o que mostra a necessidade de intensificar os esforços para a busca de novas terapias. Dessa forma, pesquisas que buscam novos compostos com atividade antimicrobiana ou que visem diminuir essa resistência tem ganhado destaque ao longo dos anos (HEMAISWARYA, KRUTHIVENTI, DOBLE, 2008).

O uso de plantas medicinais no tratamento de doenças vem ocorrendo desde as primeiras civilizações. O conhecimento sobre as propriedades terapêuticas dos vegetais é cumulativo às suas aplicações e tem sobrevivido ao longo do tempo e sido difundido através das gerações até a atualidade (BONIL, BUENO, 2014). Percebe-se um aumento no reconhecimento pelas informações potenciais, que o conhecimento tradicional possui, especialmente em pesquisas que buscam a partir das plantas medicinais identificar seus constituintes químicos e seu potencial farmacológico (ELISABETSKY, SOUZA, 2004).

Estima-se que, existam cerca de 250.000 espécies de plantas no mundo, no entanto, a grande maioria delas tem suas propriedades e compostos químicos desconhecidos (FOGLIO et al., 2006), podendo existir alternativas para a resistência microbiana.

Além da atividade antimicrobiana, tem-se observado que alguns metabólitos secundários vegetais tem a capacidade de modificar os mecanismos de resistência bacterianos e resultados

\footnotetext{
Recebido em 05/10/2019, Aceito para publicação em 15/10/2019

${ }^{1}$ Universidade Federal do Piauí

*E-mail: samuelbarros0912@gmail.com
} 
promissores têm sido observados (CHAVES et al., 2016, 2018).

Dentre as espécies vegetais de uso medicinal, pode-se destacar Momordica charantia L., uma trepadeira pertencente à família Cucurbitaceae cresce em áreas tropicais da América do Sul e Central, Ásia e Leste da África, sendo intensamente utilizado nos sistemas médicos locais (GROVER, IADAV, 2004).

Todas as suas partes apresentam sabor amargo e são indicados para o tratamento de algumas afecções, como: Inflamações hepáticas, problema de pele, tosse, diabetes, infecções parasitárias (ALBUQUERQUE et al., 2007; ASSIS et al., 2015).

Estudos fitoquímicos revelaram a presença de diversos compostos ativos, como alcaloides, saponinas, glicosídeos, triterpenos, proteínas e esteroides (RAMAN, LAU, 1996). Experimentos farmacológicos confirmaram que $M$. chatantia apresenta atividade antidiabética (KAR et al., 2003), Antiulcerogênica (GURBUZ et al., 2000), Antibacteriana (KHAN, OMOLOSO, 1998), dentre outras.

$\mathrm{O}$ estudo teve como objetivo avaliar in vitro o potencial do extrato de $M$. charantia como agente antibacteriano e modulador da resistência de cepas de Escherichia coli a antibióticos de diferentes classes.

\section{MATERIAL E MÉTODOS}

As folhas de $M$. charantia L., foram coletadas na zona rural de Bom Jesus, Sul do estado do Piauí,

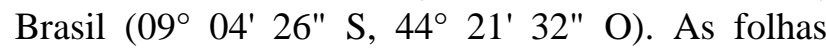
coletadas foram dessecadas em estufa de circulação de ar em temperatura de $40{ }^{\circ} \mathrm{C}$, e posteriormente trituradas. Após esta etapa, 200 gramas da planta foram submetidos ao processo de extração por maceração com $1000 \mathrm{~mL}$ de etanol absoluto por cinco dias à temperatura ambiente $\left(25 \pm 3^{\circ} \mathrm{C}\right)$. Após a filtragem, o extrato foi concentrado em evaporador rotativo a $40{ }^{\circ} \mathrm{C}$, obtendo-se o extrato etanólico de Momordica charantia (EEMc).

As cepas multirresistentes utilizadas foram as $E$. coli 35 , produtoras de $\beta$-lactamase (resistente a antibióticos $\beta$-lactâmicos) e a $E$. coli 208 , resistente a gentamicina, sulfametoxazol-trimetropim, cefalexina, ampicilina, ciprofloxacino, ampicilina e cefamicina. As cepas foram mantidas em tubos inclinados de Ágar Mueller-Hinton, sendo, antes dos ensaios, cultivadas a $37{ }^{\circ} \mathrm{C}$ por 24 horas, em placas com o mesmo meio de cultura.

A concentração inibitória mínima (CIM) foi determinada pelo método de microdiluição em placas de 96 cavidades (CLSI, 2012), usando caldo Mueller-Hinton. Colônias dos microrganismos foram suspensas em solução salina $0,9 \%$, até atingirem a turbidez correspondente ao tubo $0,5 \mathrm{da}$ escala de Mac-Farland.

Foram realizadas diluições seriadas do extrato em um intervalo de concentrações entre 1000 e 3,9 $\mu \mathrm{g}$ $\mathrm{mL}^{-1}$. A solução de DMSO a $10 \%$, utilizada para diluir os extratos foi utilizada como controle negativo. Posteriormente, as placas foram incubadas a $37 \pm 1{ }^{\circ} \mathrm{C}$, durante 24 horas. $\mathrm{O}$ crescimento bacteriano foi indicado pela adição de $20 \mu \mathrm{L}$ de solução aquosa de resazurina a $0,01 \%$, com nova incubação a $37{ }^{\circ} \mathrm{C} \pm 1{ }^{\circ} \mathrm{C}$, durante 2 horas. Os ensaios foram realizados em triplicata.

A avaliação dos extratos como moduladores da resistência antimicrobiana foi realizada de acordo com Coutinho et al. (2013). A CIM dos antibióticos foi determinada na presença e na ausência dos extratos em concentrações subinibitória $(125 \mu \mathrm{g} \mathrm{mL}$ ${ }^{1}$ ). Realizou-se também, análise de variância (Anova twoway), seguida pelo pós-teste de Bonferroni, utilizando o software Graphpad Prism 5.0.

\section{RESULTADOS E DISCUSSÕES}

A partir dos resultados obtidos após análise microbiológica, pôde-se perceber que o extrato vegetal da $M$. charantia $L$. não teve efeito inibitório frente as cepas multirresistentes de E. coli testadas $\left(\mathrm{CIM}>1000 \mu \mathrm{g} \mathrm{mL}^{-1}\right)$. Em contraste, Costa et al. (2010) observaram em suas análises que o extrato etanólico e frações de $M$. charantia apresentaram atividade inibitória frente a cepas padrão e multirresistente de E. coli, com valores de CIM variando entre 32 e $512 \mu \mathrm{g} \mathrm{mL}^{-1}$. A divergência nesses resultados pode ser explicada pela diferença nas condições ambientais as quais as plantas coletadas nos dois estudos estavam submetidas, o que influencia diretamente na composição química e concentração dos metabólitos secundários (CHAVES et al., 2013), além do perfil fenotípico de resistência das cepas bacterianas.

A associação de extratos de plantas com características medicinais junto a antimicrobianos, pode atuar potencializando a capacidade de inibição de um antimicrobiano sintético, ou potencializando os efeitos deste sobre o microrganismo (HEMAISWARYA et al., 2008).

Nos ensaios em que houve a associação do extrato da espécie $M$. charantia $\mathrm{L}$. com os diferentes antibióticos (Figura 1) junto a E. coli 35 observou-se uma redução significativa da CIM apenas para Amoxicilina $\left(99,2\right.$ para 50,0 $\left.\mu \mathrm{g} \mathrm{mL}^{1}\right)$. Com a Gentamicina e Vancomicina o extrato não apresentou efeito significativo na CIM. 


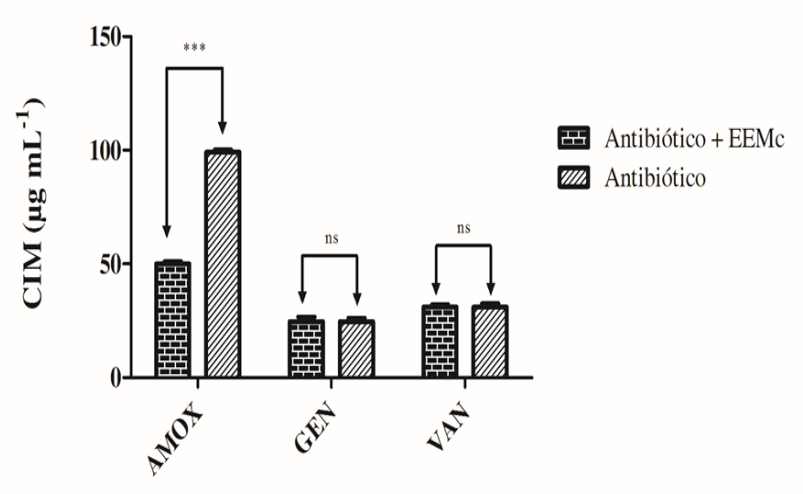

Figura 1: Atividade moduladora do extrato vegetal da Momordica charantia L., frente a resistência de Escherichia coli 35 sobre antibióticos. *** - Diferença estatisticamente significativa $(\mathrm{P}<0,01) ; \mathrm{ns}$ - diferença estatisticamente não significativa (P>0,05); AMOX - Amoxicilina; GEN - Gentamicina; VAN Vancomicina.

Nos ensaios com E. coli 208 após a associação do extrato de $M$. charantia L. (Figura 2), com os diferentes antimicrobianos, verificou-se que houve redução da CIM da amoxicilina (396,8 para 250,0 $\left.\mu \mathrm{g} \mathrm{mL}^{-1}\right)$ e gentamicina $\left(62,5\right.$ para $\left.39,3 \mu \mathrm{g} \mathrm{mL}^{-1}\right)$, enquanto que, a associação do extrato com a Vancomicina não apresentou diferença significativa.

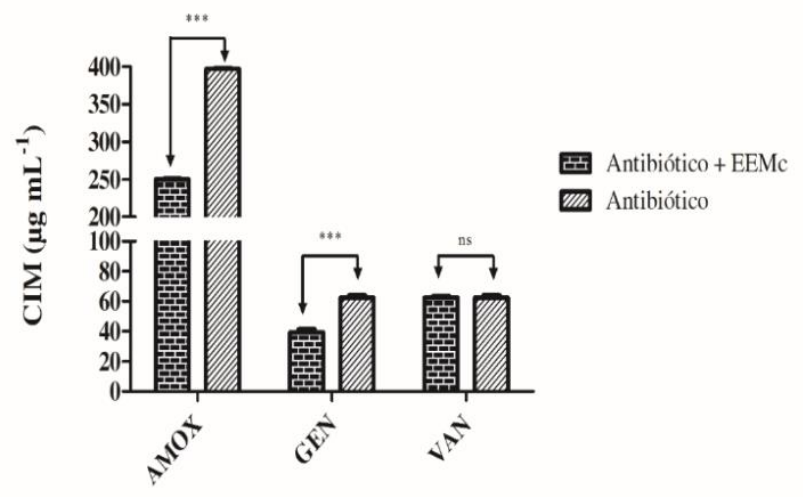

Figura 2: Atividade moduladora do extrato vegetal de Momordica charantia L., frente a resistência de Escherichia coli 208 sobre antibióticos. *** - Diferença estatisticamente significativa $(\mathrm{P}<0,01)$; ns - diferença estatisticamente não significativa $(\mathrm{P}>0,05)$; AMOX - Amoxicilina; GEN Gentamicina; VAN - Vancomicina.

Há relatos na literatura da associação de produtos naturais extraídos de $M$. charantia e antimicrobianos sintéticos. Em estudos realizados por Coutinho et al., (2010) o extrato de $M$. charantia potencializou o efeito dos aminoglicosídeos gentamicina, canamicina e neomicina em ensaios com cepas de $S$. aureus resistentes à meticilina (MRSA). No estudo realizado por Costa et al., (2010), no qual foi realizada a associação de diferentes extratos e frações de $M$. charantia e aminoglicosideos, em muitos casos observou-se efeito sinérgico sobre cepas de E. coli e S. aureus.
Os melhores resultados deste estudo foram obtidos a partir da associação do extrato com amoxicilina, que é um antibiótico $\beta$-lactâmico. Estes antimicrobianos atuam ligando-se a proteínas ligadoras de penicilina (PBP) e inutilizando-as. Estas proteínas são responsáveis pela síntese e estruturação dos peptidoglicanos na parede bacteriana e, caso haja sua inativação, será formada uma parede mecanicamente mais fraca que não suporta alterações na pressão osmótica, o que leva as bactérias à morte através da lise celular (TENOVER, 2006).

Os mecanismos de resistência a estes antibióticos incluem (1) a substituição das PBP por outras proteínas com menores afinidades aos antimicrobianos; (2) produção de enzimas $\beta$ lactamases, que rompem o anel $\beta$-lactâmico do antibiótico, inativando-o; e (3) redução do acesso do antibiótico às PBP alvo através de alterações de permeabilidade da membrana bacteriana externa ou a presença de bombas de efluxo (LEVY, MARSHALL, 2004).

Uma estratégia que vem sendo utilizada visando atenuar este problema é a associação de fármacos com produtos naturais ou sintéticos que tenham a capacidade de suprimir os mecanismos de resistência. A combinação de antimicrobianos $\beta$ lactâmicos e produtos naturais tem apresentado resultados positivos (FIGUEREDO et al., 2013, 2014). A amoxicilina, ao ser associada a produtos naturais também teve seu efeito potencializado (CHAVES et al., 2018).

Estudos fitoquímicos realizados com $M$. charantia revelaram a presença de uma gama de metabólitos secundários, tais como taninos, flavonoides, alcaloides, triterpenos e esteroides (RODRIGUES et al. 2010; COSTA et al., 2010).

Muitos desses compostos apresentam importantes atividades farmacológicas, entre elas, atividade antimicrobiana. Os taninos podem provocar inibição enzimática, ruptura da membrana e formar complexos com a parede celular, interferindo em seu funcionamento (COWAN, 1999). Alcaloides podem atuar na inibição da síntese de ácidos nucleicos, da divisão celular, interferindo na homeostase bacteriana e comprometer a estrutura das membranas bacterianas (CUSHNIE et al., 2014). Flavonoides podem provocar danos à membrana celular, provocando aberturas e modificando a permeabilidade, inibição da síntese de ácidos nucleicos e inibição do metabolismo energético (CUSHNIE, LAMB, 2011).

Também são descritas a combinação de alguns destes produtos e antimicrobianos sintéticos. Flavonoides apresentaram efeito sinérgico quando associados a diferentes antimicrobianos $\beta$-lactâmicos (FUJITA et al., 2005; EUMKEB et al., 2010). De 
maneira similar, alcaloides apresentaram efeito sinérgico quando combinados com antimicrobianos de diferentes classes, como aminoglicosídeos, $\beta$ lactâmicos e quinolonas (CUSHNIE et al., 2014).

\section{CONCLUSÕES}

Os ensaios microbiológicos demonstraram que o extrato da $M$. charantia L. não inibiu o crescimento de cepas de E. coli multirresistentes. No entanto, a associação do extrato com antibióticos potencializou a atividade da Gentamicina sobre E. coli 208 e especialmente Amoxicilina sobre as duas cepas testadas.

Futuros estudos são necessários para esclarecer quais componentes são responsáveis pela atividade antimicrobiana da $M$. charantia L. e os mecanismos envolvidos nesse processo.

\section{REFERÊNCIAS BIBLIOGRÁFICAS}

ALBUQUERQUE, U. P.; MEDEIROS, P. M.; ALMEIDA, A. L. S.; MONTEIRO, J. M.; LINS NETO, E. M. D. F.; MELO, J. G.; SANTOS, J. P. Medicinal plants of the caatinga (semi-arid) vegetation of NE Brazil: a quantitative approach. Journal of Ethnopharmacology, v. 114, n. 3, p. 325-354, 2007.

ASSIS, J. P.; SOUSA, S. P.; LINHARES, P. C. F.; PEREIRA, M. F. S.; MOREIRA, J. C. Avaliação biométrica de caracteres do melão de São Caetano (Momordica charantia L.). Revista Brasileira de Plantas Medicinais, v. 17, n. 4, p. 505-514, 2015.

BONIL, L. N.; BUENO, S. M.; Plantas medicinais: benefícios e malefícios. 2014.

CHAVES, T. P. FERNANDES, F. H. A., SANTANA, C. P., SANTOS, J. S., MEDEIROS, F. D., FELISMINO, D. C.; SANTOS, V. L.; CATÃO, R. M. R.; COUTINHO, H. D. M.; MEDEIROS, A. C. D. Evaluation of the interaction between the Poincianella pyramidalis (Tul.) LP Queiroz extract and antimicrobials using biological and analytical models. PloS one, v. 11, n. 5, p. e0155532, 2016.

CHAVES, T. P.; PINHEIRO, R. E. E.; MELO, E. S.; SOARES, M. J. D. S.; SOUZA, J. S. N.; DE ANDRADE, T. B.; LEMOS, T. L. G.; COUTINHO, H. D. M. Essential oil of Eucalyptus camaldulensis Dehn potentiates $\beta$ lactam activity against Staphylococcus aureus and Escherichia coli resistant strains. Industrial Crops and Products, v. 112, p. 70-74, 2018.

CHAVES, T. P.; SANTANA, C. P.; VÉRAS, G.; BRANDÃO, D. O.; FELISMINO, D. C.; MEDEIROS, A. C. D.; TROVÃO, D. M. B. M. Seasonal variation in the production of secondary metabolites and antimicrobial activity of two plant species used in Brazilian traditional medicine. African Journal of Biotechnology, v. 12, p. 847-853, 2013.

CLSI-Clinical and Laboratory Standards Institute. 2012. Performance Standards for Antimicrobial Susceptibility
Testing. Twenty Second Informational Supplement. 9th ed. Document M100-S22.

COSTA, J. G. M.; NASCIMENTO, E. M.; CAMPOS, A. R.; RODRIGUES, F. F. Antibacterial activity of Momordica charantia (Curcubitaceae) extracts and fractions. Journal of basic and clinical pharmacy, v. 2, n. 1, p. 45,2010 .

COUTINHO, H. D. M.; BRITO, S. M. O.; LEITE, N. F.; VANDESMET, V. C. S.; OLIVEIRA, M. T. A.; MARTINS, G. M. A.; SILVA, A. R. P.; COSTA, M. S. Avaliação comparativa da modulação de antibióticos, frente às cepas bacterianas de Escherichia coli, Staphylococcus aureus. Revista Ciência Saúde, v. 13, n. 3, p. 345-354, 2013.

COUTINHO, H. D. M.; COSTA, J. G.; FALCÃOSILVA, V. S.; SIQUEIRA-JÚNIOR, J. P.; LIMA, E. O Effect of Momordica charantia L. in the resistance to aminoglycosides in methicilin-resistant Staphylococcus aureus. Comparative immunology, microbiology and infectious diseases, v. 33, n. 6, p. 467-471, 2010.

COWAN, M. M. Plant products as antimicrobial agents. Clinical microbiology reviews, v. 12, n. 4, p. 564-582, 1999.

CUSHNIE, T. P. T.; CUSHNIE, B.; LAMB, A. J. Alkaloids: an overview of their antibacterial, antibioticenhancing and antivirulence activities. International Journal of Antimicrobial Agents, v. 44, n. 5, p. 377386, 2014.

CUSHNIE, T. P. T.; LAMB, A. J. Recent advances in understanding the antibacterial properties of flavonoids. International journal of antimicrobial agents, v. 38, n. 2, p. 99-107, 2011.

ELISABETSKY, E.; SOUZA, G. C. Etnofarmacologia como ferramenta na busca de substâncias ativas. SIMÕES, C. M. O.; SCHENKEL, E. P.; GOSMANN, G.; MELLO, J. C. P.; MENTZ, L. A.; PETROVICK, P. R. (Org.). Farmacognosia: da planta ao medicamento., $v$. 2, p. 87-99, 2004.

EUMKEB, G.; SAKDARAT, S.; SIRIWONG, S. Reversing $\beta$-lactam antibiotic resistance of Staphylococcus aureus with galangin from Alpinia officinarum Hance and synergism with ceftazidime. Phytomedicine, v. 18, n. 1, p. 40-45, 2010.

FIGUEREDO, F. G.; FERREIRA, E. O.; LUCENA, B. F. F.; TORRES, C. M. G.; LUCETTI, D. L.; LUCETTI, E. C. P.; SILVA, J. M. F. L.; SANTOS, F. A. V.; MEDEIROS, C. R.; OLIVEIRA, G. M. M.; COLARES, A. V.; COUTINHO, H. D. M.; COSTA, J. G. M.; MENEZES I. R. A.; SILVA, J. C. F.; KERNTOPF, M. R.; FIGUEIREDO, P. R. L.; MATIAS, E. F. F. Modulation of the Antibiotic Activity by Extracts from Amburana cearensis A. C. Smith and Anadenanthera macrocarpa (Benth.) Brenan. BioMed Research International, v. 2013, p. 1-5, 2013. 
FIGUEREDO, F. G.; LUCENA, B. F.; TINTINO, S. R.; MATIAS, E. F.; LEITE, N. F.; ANDRADE, J. C.; RODRIGUES, F. F. Chemical composition and evaluation of modulatory of the antibiotic activity from extract and essential oil of Myracrodruon urundeuva. Pharmaceutical biology, v. 52, n. 5, p. 560-565, 2014.

FOGLIO, M. A.; QUEIROGA, C. L., SOUSA, I. D. O., RODRIGUES, R. A. F. Plantas medicinais como fonte de recursos terapêuticos: um modelo multidisciplinar. Multiciência: Construindo a história dos produtos naturais, v. 7, p. 1-8, 2006.

FUJITA, M.; SHIOTA, S.; KURODA, T.; HATANO, T.; YOSHIDA, T.; MIZUSHIMA, T.; TSUCHIYA, T. Remarkable synergies between baicalein and tetracycline, and baicalein and $\beta$--lactams against methicillin-resistant Staphylococcus aureus. Microbiology and Immunology, v. 49, n. 4, p. 391-396, 2005.

GROVER, J. K.; YADAV, S. P. Pharmacological actions and potential uses of Momordica charantia: a review. Journal of Ethnopharmacology, v. 93, n. 1, p. 123-132, 2004.

GURBUZ, I.; AKYUZ, C.; YESILADA, E.; SENER, B. Anti-ulcerogenic effect of Momordica charantia L. fruits on various ulcer models in rats. Journal of Ethnopharmacology, v. 71, n. 1-2, p. 77-82, 2000.

HEMAISWARYA, S.; KRUTHIVENTI, A. K.; DOBLE, M. Synergism between natural products and antibiotics against infectious diseases. Phytomedicine, v. 15, n. 8, p. 639-652, 2008.
KAR, A.; CHOUDHARY, B. K.; BANDYOPADHYAY, N. G. Comparative evaluation of hypoglycaemic activity of some Indian medicinal plants in alloxan diabetic rats. Journal of ethnopharmacology, v. 84, n. 1, p. 105-108, 2003.

KHAN, M. R.; OMOLOSO, A. D. Momordica charantia and Allium sativum: broadspectrum antibacterial activity. Korean Journal of Pharmacognosy, v. 29, n. 3, p. 155158, 1998.

LEVY, S. B.; MARSHALL, B. Antibacterial resistance worldwide: causes, challenges and responses. Nature medicine, v. 10, n. 12s, p. S122, 2004.

RAMAN, A.; LAU, C. Anti-diabetic properties and phytochemistry of Momordica charantia L. (Cucurbitaceae). Phytomedicine, v. 2, n. 4, p. 349-362, 1996.

RODRIGUES, K. A. F.; DIAS, C. N.; FLORENCIO, J. C.; VVILANOVA, C. M.; GONÇALVES, J. R. S.; COUTINHO-MORAES, D. F. Prospecção fitoquímica e atividade moluscicida de folhas de Momordica charantia L. Cadernos de Pesquisa, v. 17, n. 2, 2010.

TENOVER, F. C. Mechanisms of antimicrobial resistance in bacteria. American Journal of Infection Control, v. 34, n. 5, p. S3-S10, 2006. 